\title{
Operating room waste: disposable supply utilization in neurosurgical procedures
}

\author{
${ }^{*}$ Corinna C. Zygourakis, MD, ${ }^{1,2}$ Seungwon Yoon, ${ }^{6}$ Victoria Valencia, MPH, ${ }^{2,3}$ \\ Christy Boscardin, PhD, ${ }^{2,4}$ Christopher Moriates, MD, ${ }^{2,3}$ Ralph Gonzales, MD, MSPH, ${ }^{2,4,5}$ and \\ Michael T. Lawton, MD'
}

\begin{abstract}
${ }^{1}$ Department of Neurological Surgery, ${ }^{2}$ Center for Healthcare Value, ${ }^{3}$ Division of Hospital Medicine, ${ }^{4}$ Department of Medicine, and ${ }^{5}$ Continuous Process Improvement, University of California, San Francisco, California; and ${ }^{6}$ Brown University, Providence, Rhode Island
\end{abstract}

\begin{abstract}
OBJECTIVE Disposable supplies constitute a large portion of operating room (OR) costs and are often left over at the end of a surgical case. Despite financial and environmental implications of such waste, there has been little evaluation of OR supply utilization. The goal of this study was to quantify the utilization of disposable supplies and the costs associated with opened but unused items (i.e., "waste") in neurosurgical procedures.
\end{abstract}

METHODS Every disposable supply that was unused at the end of surgery was quantified through direct observation of 58 neurosurgical cases at the University of California, San Francisco, in August 2015. Item costs (in US dollars) were determined from the authors' supply catalog, and statistical analyses were performed.

RESULTS Across 58 procedures (36 cranial, 22 spinal), the average cost of unused supplies was $\$ 653$ (range \$89$\$ 3640$, median $\$ 448$, interquartile range $\$ 230-\$ 810$ ), or $13.1 \%$ of total surgical supply cost. Univariate analyses revealed that case type (cranial versus spinal), case category (vascular, tumor, functional, instrumented, and noninstrumented spine), and surgeon were important predictors of the percentage of unused surgical supply cost. Case length and years of surgical training did not affect the percentage of unused supply cost. Accounting for the different case distribution in the 58 selected cases, the authors estimate approximately $\$ 968$ of OR waste per case, $\$ 242,968$ per month, and $\$ 2.9$ million per year, for their neurosurgical department.

CONCLUSIONS This study shows a large variation and significant magnitude of OR waste in neurosurgical procedures. At the authors' institution, they recommend price transparency, education about OR waste to surgeons and nurses, preference card reviews, and clarification of supplies that should be opened versus available as needed to reduce waste.

http://thejns.org/doi/abs/10.3171/2016.2.JNS152442

KEY WORDS surgical cost; operating room; supply utilization; disposable surgical supplies

$\mathrm{I}$ $\mathrm{T}$ is well known that surgical costs are extremely high, with more than $\$ 175$ billion spent on hospital discharges associated with operating room (OR) procedures in the US in 2011. ${ }^{1}$ Disposable surgical supplies constitute a large portion of OR costs. Unfortunately, as any surgeon can attest, there are often unused or partially used supplies remaining at the end of a case, which represent a source of preventable waste. These unused supplies not only contribute to the increasing cost of health care, but also create unnecessary environmental waste. In fact, US ORs pro- duce more than 2000 tons of waste per day, ${ }^{9}$ the majority of which ends up as biohazardous waste, rather than being recycled, reused, or reduced. ${ }^{2}$

Despite financial and environmental implications of such waste, there has been relatively limited research on OR supply utilization. We found only a few studies addressing the issues of OR waste recycling ${ }^{3,6,7,9}$ and overseas donations. ${ }^{5,8}$ In particular, 2 studies from Yale-New Haven hospital in the 1990s showed that relatively large quantities of unused surgical supplies were able to be recovered

ABBREVIATIONS IQR = interquartile range; OR = operating room; UCSF = University of California, San Francisco.

SUBMITTED October 20, 2015. ACCEPTED February 5, 2016.

INCLUDE WHEN CITING Published online May 6, 2016; DOI: 10.3171/2016.2.JNS152442.

* Dr. Zygourakis and Mr. Yoon contributed equally to this work. 
for overseas donations, suggesting a significant amount of OR waste..$^{5,8}$ Only 1 study, however, tried to identify disposable medical supplies that were unnecessarily opened for each case, discovering approximately $\$ 11$ of unused disposable supplies per tonsillectomy case. ${ }^{4}$

Based on these findings and our own observations in the OR, we predicted that there were even greater amounts of preventable OR waste in neurosurgery. The goal of our study was therefore to quantify the utilization of disposable surgical supplies and to perform the first analysis of the costs associated with opened but unused items (i.e., "waste") across a range of neurosurgical procedures at our institution.

\section{Methods \\ Data Collection}

We collected data from 58 adult neurosurgical cases at the University of California, San Francisco (UCSF), in August 2015. Cases were not consecutive, but rather reflected all cases that a single observer (S.Y.) could attend with nonoverlapping end times.

For each case, patient demographics, procedure type, and case length (in minutes) were recorded. Surgeon name and years of training postresidency were also collected. Disposable surgical supplies were defined as 1-time use items in the operating room (such as sutures, gloves, drill bits), and included both individual items as well as items in larger packs (for example, our "basic spine pack" or "neurovascular pack"). For each case and surgeon, we also recorded whether the surgeon had an individually customized pack for that case type (e.g., the "Lawton neurovascular pack"). One observer (S.Y.) cataloged each disposable surgical supply that was left at the end of the case (approximately 200 work hours). If a supply had multiple components, such as 10 sutures in a pack, the observer counted the number of unused sutures remaining. Unused supplies, or "OR waste," were defined as any disposable supplies that were left at the end of the case that were not used in the surgery (that is, did not touch the surgeon's hand or the patient). The item cost in US dollars for each of these unused supplies was determined from the UCSF supply catalog (which reflects proprietary UCSF negotiated rates), and was summed to determine the total cost of unused supplies for the case. The total supply costs for each case were determined from the electronic medical record (Epic Systems, Inc.) and included the costs of all surgical supplies found on that patient's hospital bill.

\section{Statistical Analysis}

Data aggregation and exploratory analysis were performed in Microsoft Excel (version 14.2.5), and values were expressed as averages \pm standard deviations, or medians \pm interquartile ranges (IQRs) where appropriate. The statistical program JMP (version 12.0, SAS Institute Inc.) was used to perform Student t-tests, Wilcoxon ranksum tests, chi-square tests, and 1-way ANOVAs, where appropriate. To control for the effect of surgeon clustering on percentage unused supply cost, we created mixed models in JMP, with the surgeon as a random effect, and case type (cranial vs spine), case category (vascular, tu- mor, functional, instrumented spine, and noninstrumented spine), and case length as fixed effects.

\section{Results \\ Case Types}

We observed 58 neurosurgical procedures, including 36 cranial and 22 spinal cases, performed by 14 different surgeons. The average operative time was 326 minutes, ranging from 116 minutes (approximately 2 hours) to 673 minutes ( $>11$ hours). The number of cases performed by a single surgeon ranged from 1 to 13 . These included a wide variety of neurosurgical cases, from craniotomies for aneurysmal clip placements to brain tumor resections, epilepsy cases, and spinal fusions. Table 1 shows the distribution of case types (cranial, spinal, and other) and case categories (vascular, tumor, functional, instrumented spine, noninstrumented spine, and other) in our 58 observed cases and all 251 neurosurgical cases performed that month at our institution.

\section{Total and Unused Surgical Supply Costs}

Across our 58 observed cases, the average total surgical supply costs were $\$ 8377 \pm \$ 9578$ (median $\$ 4801$, IQR \$6416). As expected, spine cases had higher surgical supply costs than cranial cases (average $\$ 14,899 \pm \$ 12,985$ vs $\$ 4392 \pm \$ 2275$, respectively; median $\$ 12,102 \pm \$ 14,595$ vs $\$ 3569 \pm \$ 2968$, respectively; $p<0.004$, Wilcoxon ranksum test; Table 2). Figure 1 shows an example of unused supplies at the end of 2 neurosurgical cases. The average cost of unused or wasted supplies across all cases was $\$ 653 \pm \$ 710$ (median \$448, IQR \$230-\$810), or $13.1 \%$ of the total surgical supply cost (Table 2). The range in cost of unused supplies was $\$ 89$ to $\$ 3640$ per case; this significant case-to-case variation is shown in Fig. 2.

\section{Most Frequently Wasted Supplies}

The most frequently wasted supplies are shown in Table 3. As expected, these supplies include commonly used low-cost items such as sponges, gloves, and sutures. How-

TABLE 1. Characteristics of 58 observed neurosurgical cases versus all 251 neurosurgical cases performed in August 2015

\begin{tabular}{lcc}
\hline \multicolumn{1}{c}{ Variable } & Observed Cases (\%) & All Cases $(\%)$ \\
\hline Case type & & \\
\hline Cranial & $36(62)$ & $152(61)$ \\
\hline Spinal & $22(38)$ & $90(36)$ \\
\hline Other & $0(0)$ & $9(4)$ \\
\hline Case category & & \\
\hline Vascular & $14(24)$ & $25(10)$ \\
\hline Tumor & $18(31)$ & $88(35)$ \\
\hline Functional & $4(7)$ & $29(12)$ \\
\hline Instrumented spine & $19(33)$ & $66(26)$ \\
\hline Noninstrumented spine & $3(5)$ & $22(9)$ \\
\hline Other† & $0(0)$ & $21(8)$ \\
\hline
\end{tabular}

* Denotes neither cranial nor spinal surgeries, such as peripheral nerve cases. † Includes peripheral nerve cases, ventriculoperitoneal shunts, and lumboperitoneal shunts. 
TABLE 2. Average total surgical supply and unused surgical supply costs across all observed neurosurgical procedures

\begin{tabular}{cc}
\hline \multicolumn{1}{c}{ Variable } & Average Costs (SD) \\
\hline Total surgical supplies (all) & $8377(9578)$ \\
\hline Cranial & $4392(2275)$ \\
\hline Spine & $14,899(12,985)$ \\
\hline Unused surgical supplies (all) & $653(710)$ \\
\hline Individual items & $554(691)$ \\
\hline Pack items & $99(96)$ \\
\hline Cranial & $715(691)$ \\
\hline Spinal & $551(745)$ \\
\hline Custom packs & $316(792)$ \\
\hline General packs & $792(799)$ \\
\hline
\end{tabular}

* All costs given in US dollars.

ever, the most costly waste comes from less frequently used but higher-cost supplies such as hemostatic agents (e.g., Floseal), sealants (e.g., DuraSeal), and screws (Table $3)$. The majority of unused items represented individually opened items (average $\$ 554 \pm \$ 691$ per case, or $85 \%$ of all unused items), rather than unused items within large packs $(\$ 99 \pm \$ 96$ per case, or $15 \%$ of all unused items; Table 2).

\section{Predictors of the Percentage of Unused Surgical Supplies}

We performed univariate analyses to determine the factors predictive of surgical supply waste. We chose to look at percentage unused surgical supply cost, rather than surgical supply cost in dollars, as certain cases use more expensive supplies at baseline, such as spinal fusion procedures. Univariate analyses revealed that case type, case category, and surgeon were significant predictors of the percentage of unused surgical supplies (Table 4). More specifically, we found a significantly lower percentage of unused supplies in spinal versus cranial cases $(7.18 \%$ vs $16.2 \%, \mathrm{p}=$ $0.008)$. We also found that case category was an important predictor of unused surgical supplies, with tumor and functional cases having higher percentages of unused supplies (19.7\% and 19.6\%, respectively) than vascular or instrumented spine cases $(9.96 \%$ and $6.58 \%$, respectively; $p$ $=0.006$, Table 4). Similarly, we found significant variation in the percentage of unused supply costs between surgeons, with 1 spine surgeon having as low as $1.9 \%$ wasted surgical supplies and 1 tumor surgeon having a much higher average of $23.6 \%$ wasted surgical supplies $(p=0.026$; Table 4). At our institution, neurosurgeons are highly specialized, resulting in a high degree of correlation between surgeon and case category (i.e., spine surgeons perform only spine cases, tumor surgeons only specific types of tumor cases; $\mathrm{p}<0.001$, chi-square test). We therefore could not assess whether case category or surgeon had a larger impact on the percentage of unused supplies.

Univariate analyses also revealed that customized packs, case length, and surgical years of training did not affect the percentage of surgical supply cost. More specifically, surgeons using customized packs did not have a significantly different percentage of unused supplies compared with those using general packs $(\mathrm{p}=0.955$; Tables 2 and 4). We also did not find a statistically significant effect
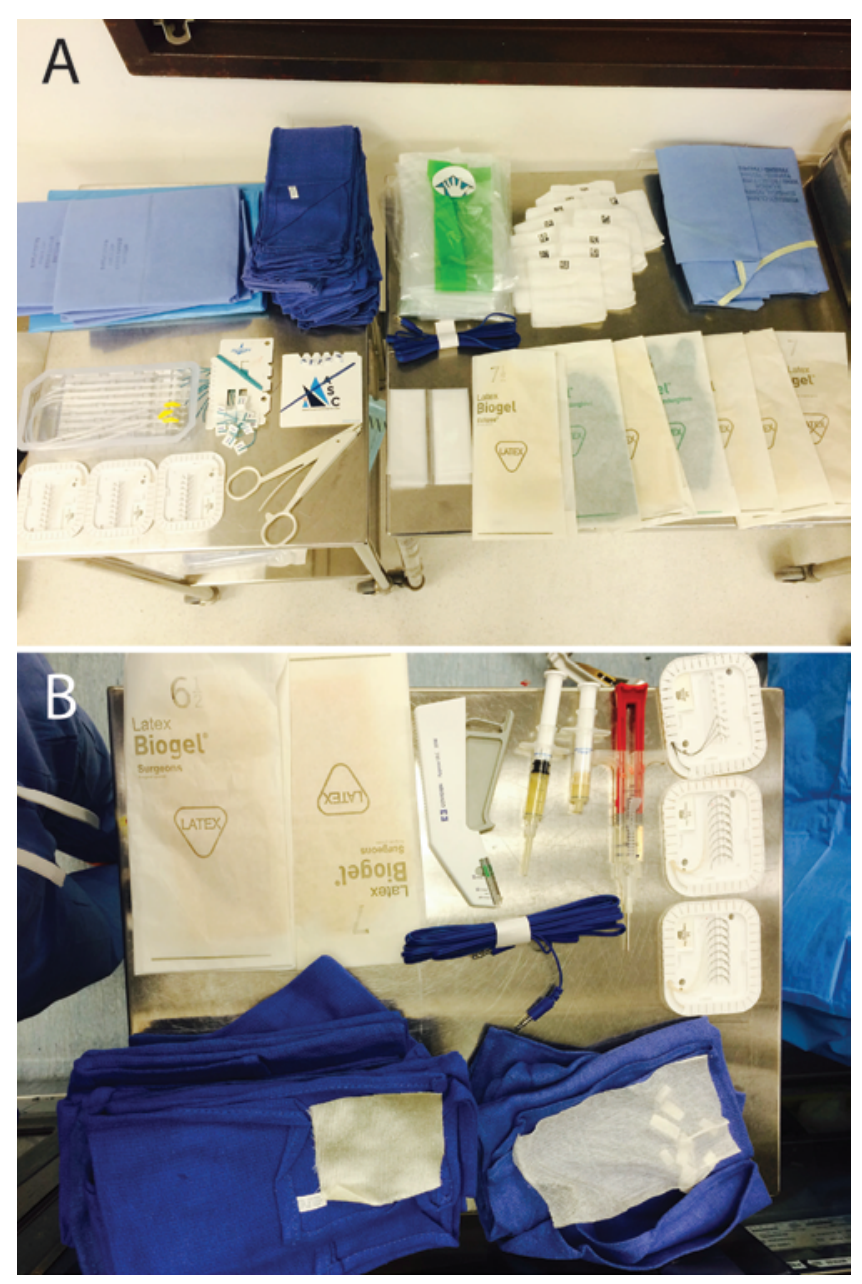

FIG. 1. Preoperative or postoperative? Both of these photographs demonstrate unused supplies, including gloves, sutures, and hemostatic agents such as Surgicel (Ethicon), Nu-knit (Ethicon), and Floseal (Baxter), from the end of a neurosurgical procedure.

of case length or years of surgical training on percentage of unused supplies $(\mathrm{p}=0.096$ and $\mathrm{p}=0.169$, respectively; Table 5). Note that we could not examine the effect of surgical trainees on unused surgical supply cost, as $56(97 \%)$ of 58 of our cases involved resident or fellow trainees.

\section{Mixed-Effect Models}

To address the nested structure of our data (because specific surgeons tend to perform certain cases) and factor confounding, we created mixed-effect models to evaluate the effect of case length, case type, and case category on percentage unused supply cost. Multivariate analysis was not feasible given the small sample size and collinearity of the variables, so we created 3 separate models (Table $6)$. These models revealed a trend toward an effect of case length $(\mathrm{p}=0.0921)$ and case type $(\mathrm{p}=0.0535)$, but not case category, on percentage unused supply cost.

Finally, to account for case selection bias, due to the day or time of case scheduling and our lack of true statistical randomization, we evaluated whether our 58 observed cases were a reasonable representation of all neurosurgical cases performed that month. The total supply cost was not 


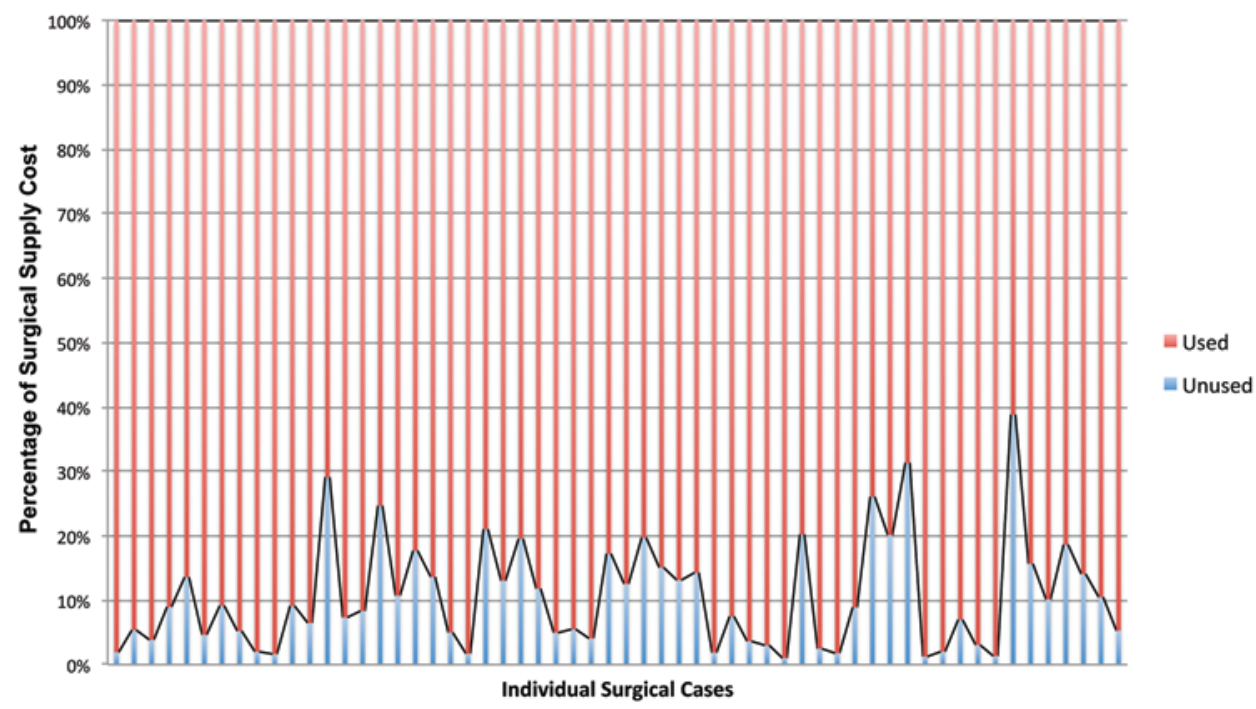

FIG. 2. Graph of the percentages of unused supplies across 58 neurosurgical procedures at UCSF in August 2015.

statistically significantly different between our 58 cases and the entire set of 251 neurosurgical cases performed that month $(\$ 8377 \pm \$ 9578$ vs $\$ 7591 \pm \$ 9528 ; p=0.575$, Student t-test). Although Table 1 shows similar cranial versus spinal case distributions between our observed cas-

TABLE 3. Ten most frequently wasted surgical supplies, and top 10 most expensive wasted surgical supplies, across 58 neurosurgical cases

\begin{tabular}{|c|c|c|}
\hline Variable & $\begin{array}{l}\text { Cases in Which } \\
\text { Specific Item } \\
\text { Was Wasted }\end{array}$ & $\begin{array}{l}\text { Total Cost } \\
\text { of Wasted } \\
\text { Items (\$) }\end{array}$ \\
\hline \multicolumn{3}{|l|}{ Most frequently wasted supplies } \\
\hline $\begin{array}{l}\text { Raytex sponge gauze }(4 \times 4 \text { inch, } \\
\text { 10/pack) }\end{array}$ & 54 & 25.40 \\
\hline $1 / 2 \times 1 / 2$-inch sponge (10/pack) & 53 & 374.12 \\
\hline Gloves & 43 & 180.67 \\
\hline OR blue towel & 42 & 243.81 \\
\hline $1 \times 1$-inch sponge (10/pack) & 40 & 294.79 \\
\hline $1 / 2 \times 1$-inch sponge (10/pack) & 31 & 209.17 \\
\hline Surgicel Nu-Knit (3 × 4 inch) & 30 & 1264.31 \\
\hline 2-0 Vicryl suture (8/pack) & 26 & 300.88 \\
\hline Surgifoam & 26 & 3749.87 \\
\hline Delicot sponge (10/pack) & 24 & 217.36 \\
\hline \multicolumn{3}{|l|}{ Most expensive wasted supplies } \\
\hline Surgifoam & 26 & 3749.87 \\
\hline Tisseel (4 ml) & 16 & 3495.33 \\
\hline Floseal (5 ml) & 18 & 3246.81 \\
\hline Expedium polyaxial screw & 3 & 3144.00 \\
\hline DuraGen $(3 \times 3$ inches) & 7 & 2023.64 \\
\hline Drill bit & 16 & 2002.19 \\
\hline HydroSet cement (10 ml) & 1 & 1950.00 \\
\hline DuraSeal (5 ml) & 4 & 1729.14 \\
\hline Surgicel Nu-Knit ( $3 \times 4$ inches) & 30 & 1264.31 \\
\hline Surgisis $(2 \times 3$ inches $)$ & 3 & 1141.60 \\
\hline
\end{tabular}

es and all neurosurgeries that month $(\mathrm{p}=0.341$, chi-square test), we also see an overrepresentation of vascular cases (24\% vs 10\%) and an underrepresentation of "other" cases (such as peripheral nerve cases and shunts, 0 vs $8 \%$; $\mathrm{p}<$ 0.0001 , chi-square test) in our observed cases. Given that vascular cases had lower percentage unused supply costs compared with nearly all other case categories, this would suggest that our average waste of $\$ 653$ is actually an underestimate of neurosurgical waste at our institution.

We therefore performed a weighted estimate of OR waste per case and per month, based on the exact distribution of case categories performed in August 2015

TABLE 4. Univariate analysis of categorical surgical variables on percentage unused surgical supply cost*

\begin{tabular}{|c|c|c|c|}
\hline Variable & $\begin{array}{c}\text { Mean \% Unused } \\
\text { Supply Cost }\end{array}$ & $95 \% \mathrm{Cl}$ & $p$ Value \\
\hline Case Type & & & $0.0075 \dagger$ \\
\hline Cranial & 16.2 & $12.4-20.0$ & \\
\hline Spinal & 7.18 & $1.92-12.4$ & \\
\hline Case Category & & & $0.0061 \dagger$ \\
\hline Vascular & 9.96 & $3.92-16.0$ & \\
\hline Tumor & 19.7 & $14.4-25.1$ & \\
\hline Functional & 19.6 & $8.26-30.9$ & \\
\hline Instrumented spine & 6.58 & $1.39-11.8$ & \\
\hline Noninstrumented spine & 20.2 & $7.11-33.2$ & \\
\hline Surgeon & & & $0.0259 \dagger$ \\
\hline Surgeon 1 & 1.9 & -20.4 to 24.2 & \\
\hline Surgeon 14 & 23.6 & $16.5-30.6$ & \\
\hline Pack & & & 0.9548 \\
\hline Custom & 12.9 & $7.02-18.9$ & \\
\hline Generic & 13.1 & $9.17-17.1$ & \\
\hline $\begin{array}{l}\mathrm{Cl}=\text { confidence interval. } \\
\text { * Percentage unused surgic } \\
\text { divided by total surgical sup } \\
\dagger \text { Statistically significant }(p\end{array}$ & $\begin{array}{l}\text { ply cost = unus } \\
\text { t. }\end{array}$ & surgical supp & cost \\
\hline
\end{tabular}

J Neurosurg Volume 126 • February 2017 
TABLE 5. Univariate analysis of continuous surgical variables on percentage unused surgical supply cost

\begin{tabular}{cccc}
\hline Surgical Variable & Estimate & Standard Error & p Value \\
\hline Case length (min) & -0.0002 & 0.0001 & 0.096 \\
\hline $\begin{array}{c}\text { Surgeon yrs of training } \\
\text { (post-residency) }\end{array}$ & 0.003 & 0.002 & 0.169 \\
\hline
\end{tabular}

(Table 1) and the average percentage unused supply cost for each case category (Table 4). This revealed an estimated $\$ 968$ of OR waste per neurosurgical case. Extrapolated to all neurosurgical cases performed at our institution, this is an estimated $\$ 242,968$ of OR waste in August 2015, or approximately $\$ 2.9$ million per year, for our neurosurgical department.

\section{Discussion}

In summary, our work shows that that there is a large variation and significant magnitude of preventable OR waste (an estimated average of $\$ 968$ per neurosurgical case), much higher than that suggested by prior studies of recoverable materials for international donations ${ }^{5,8}$ or documentation of waste in tonsillectomy procedures. ${ }^{4}$ Our calculations may actually represent underestimates of true OR waste, both due to selection bias (namely, overrepresentation of low-waste vascular cases, which we have corrected for in our extrapolations), as well as the fact that nurses commented they were less likely to open disposable supplies when they knew they were under observation. The tendency in surgery to anticipate needs and emergencies may explain overpreparedness and some OR waste.

Our univariate analyses show that case type (spinal vs cranial), case category (vascular, tumor, functional, instrumented, and noninstrumented spine), and surgeon are important predictors of the percentage of unused supplies. This suggests that we could make significant steps toward reducing OR waste by focusing on our high-waste cases (such as tumor and functional cases) and high-waste surgeons. To reduce waste at our institution, we recommend the following comprehensive strategy: 1) price transparency for surgeons; 2) education about waste to nurses and surgeons, especially high-waste surgeons; 3) careful review of surgeon preference cards to remove unnecessary items, with special attention paid to high-waste surgeries; and 4) clarification of which implants should be opened onto the sterile field, versus available in the room as needed.

To promote price transparency, we have developed surgeon snapshots showing the median surgical supply cost for each type of surgery that the surgeon performed in the prior month, compared with the surgeon's baseline performance (January 2012 to December 2014) and the performance of all UCSF surgeons performing the same procedure over the baseline period. We are giving these snapshots to surgeons in the departments of neurosurgery, orthopedic surgery, and otolaryngology and head and neck surgery every month, and we are tracking if this price transparency information reduces their overall surgical costs. In addition, we are educating surgeons and nurses at department meetings about the degree of OR
TABLE 6. Mixed-effect models of surgical variables on percentage unused surgical supply cost

\begin{tabular}{cc}
\hline \multicolumn{1}{c}{ Model } & p Value \\
\hline Model 1 & 0.0921 \\
\hline Surgeon (random effect) & \\
\hline Case length (fixed effect) & 0.0535 \\
\hline Model 2 & \\
\hline Surgeon (random effect) & 0.3017 \\
\hline Case type (fixed effect) & \\
\hline Model 3 & \\
\hline Surgeon (random effect) & \\
\hline Case category (fixed effect) &
\end{tabular}

waste and the cost of specific high-cost implants, such as those detailed in Table 3. In these sessions, we are emphasizing the importance of communication between surgeon and nurse at the beginning of the case to determine which high-cost implants will be needed. Finally, our administration is supporting a hospital-wide preference card and instrument set review, whose goal is to increase efficiency and eliminate waste in the OR. An important aspect of the preference card reviews is removing unnecessary items (to prevent them from being opened reflexively by the nurse before the case start) and clarifying specifically which items should be opened onto the sterile field, versus available in the room as needed.

Another important finding is that the surgeon's years of training are not correlated with the percentage of unused supply cost. Thus, more experienced neurosurgeons do not operate more efficiently or produce less waste than their younger counterparts. In addition, the majority $(85 \%)$ of OR waste comes from individual disposable items, rather than items in larger packs. This indicates that if we educate surgeons and nurses about OR waste, clean up preference cards, and encourage communication at the beginning of each case about what items will be needed, we may be able to significantly reduce OR waste without having to completely overhaul our entire supply packs.

A major limitation of this work is our small sample size, which is constrained by the significant manpower needed to perform direct observation of every surgical case. Unfortunately, data on OR waste is not available through automatic review of the electronic medical record or inventory tracking database, because we are specifically trying to identify supplies that are opened (and hence depleted from our inventory and marked as "used" in the electronic medical record) but not actually used by the surgeon in the case. The only accurate way to capture this waste was through direct observation, as we did in this study. Due to our small sample size, we should interpret our statistical results with caution. In addition, our work is subject to selection bias. Because our single observer could not attend cases with overlapping end times, we could not perform true statistical randomization for case selection. We have controlled for this by extrapolating our results to the true distribution of all cases performed that month at our institution.

Our work is also limited to 1 surgical specialty at 1 in- 
stitution. We appreciate that the cases at our tertiary referral center may not be representative of neurosurgical cases nationally, as our longer case times and higher supply costs likely reflect the greater complexity of cases at our institution. In addition, nearly all of our cases have resident or fellow trainees, which may contribute to inefficiency and preclude generalization of our findings to community hospitals. However, even if other institutions have only a fraction of the waste reported here, we believe that this is an important issue worthy of attention and further study. Future studies at our institution will be focused on whether the comprehensive strategy outlined above is successful at reducing OR waste. We should always prioritize patient care and ensure that we as surgeons are equipped with necessary tools for each procedure, but should also be mindful of the large financial and environmental costs of our waste.

\section{Conclusions}

To the best of our knowledge, our study represents the first report of the significant variation and magnitude of OR waste, or unused disposable surgical supplies, across 58 neurosurgical cases. Given the single-site nature of this study, we caution that our numerical results may not be generalizable to other institutions. However, our work suggests that there is significant OR waste, especially from higher-cost implants, and that a nontrivial portion of this waste may be preventable. At our institution, we recommend price transparency, education about OR waste to surgeons and nurses, preference card reviews, and clarification of supplies that should be opened versus available as needed to reduce waste. Such efforts are currently underway at our institution, and we believe that national, systems-level efforts to reduce OR waste will help deliver more costeffective care to our patients and benefit our environment.

\section{Acknowledgments}

Dr. Zygourakis is supported by a research fellowship from the UCSF Center for Healthcare Value.

\section{References}

1. Centers for Disease Control and Prevention: Health, United States, 2013. Hyattsville, MD: National Center for Health Statistics, 2014 (http://www.cdc.gov/nchs/data/hus/hus13. pdf\#116) [Accessed March 7, 2016]

2. Cotton RT, Cohen AP: Eco-conservation and healthcare ethics: a call to action. Laryngoscope 120:4-8, 2010

3. McGain F, Jarosz KM, Nguyen MN, Bates S, O’Shea CJ: Au- diting operating room recycling: a management case report. A A Case Rep 5:47-50, 2015

4. Penn E, Yasso SF, Wei JL: Reducing disposable equipment waste for tonsillectomy and adenotonsillectomy cases. Otolaryngol Head Neck Surg 147:615-618, 2012

5. Rosenblatt WH, Ariyan C, Gutter V, Silverman DG: Case-bycase assessment of recoverable materials for overseas donation from 1318 surgical procedures. JAMA 269:2647-2649, 1993

6. Southorn T, Norrish AR, Gardner K, Baxandall R: Reducing the carbon footprint of the operating theatre: a multicentre quality improvement report. J Perioper Pract 23:144-146, 2013

7. Stall NM, Kagoma YM, Bondy JN, Naudie D: Surgical waste audit of 5 total knee arthroplasties. Can J Surg 56:97-102, 2013

8. Wan EL, Xie L, Barrett M, Baltodano PA, Rivadeneira AF, Noboa J, et al: Global public health impact of recovered supplies from operating rooms: a critical analysis with national implications. World J Surg 39:29-35, 2015

9. Wormer BA, Augenstein VA, Carpenter CL, Burton PV, Yokeley WT, Prabhu AS, et al: The green operating room: simple changes to reduce cost and our carbon footprint. Am Surg 79:666-671, 2013

\section{Disclosures}

Dr. Zygourakis has received travel-related expenses to attend graduate education courses from Globus and Nuvasive.

\section{Author Contributions}

Conception and design: Lawton, Zygourakis, Yoon, Moriates, Gonzales. Acquisition of data: Zygourakis, Yoon, Valencia. Analysis and interpretation of data: Zygourakis, Yoon, Valencia, Boscardin, Gonzales. Drafting the article: Zygourakis, Yoon. Critically revising the article: Lawton, Zygourakis, Boscardin, Moriates, Gonzales. Reviewed submitted version of manuscript: Lawton, Zygourakis, Yoon, Valencia. Approved the final version of the manuscript on behalf of all authors: Lawton. Statistical analysis: Zygourakis, Boscardin, Gonzales. Study supervision: Lawton, Zygourakis, Gonzales.

\section{Supplemental Information \\ Previous Presentations}

These data have been accepted as an E-poster for the AANS annual meeting, April 30-May 4, 2016, in Chicago, Illinois.

\section{Correspondence}

Michael T. Lawton, Department of Neurological Surgery, University of California, San Francisco, 505 Parnassus Ave., Rm. M779, San Francisco, CA 94143. email: michael.lawton@ucsf.edu. 